\title{
1 Partnership working and organisational culture
}

\author{
Edward Peck and Helen Dickinson
}

In discussions of partnership working between health and social care agencies, one issue seems to recur more than any other: culture. Furthermore, it appears simultaneously to be both an aspiration for partnerships (e.g. to change culture) and an obstacle to partnerships (e.g. conflicts rooted in culture). This concurrent recognition of the importance of, and uncertainty about, culture is reflected in the huge volume of writings about culture in an organisational context where the term has many and varied definitions. As Scott and his colleagues (2003b) point out, '[U]nsurprisingly in view of this diverse array of phenomena, little agreement exists over a precise definition of organisational culture, how it should be observed or measured, or how different methodologies can be used to inform routine administration or organisational change' (p. 925). The aim of this chapter is to bring some clarity to discussions of culture in relation to partnership working.

Concern about culture in partnerships is not restricted to the public sector. There is compelling evidence from the private sector that culture is also a central issue in the success of alliances, mergers and acquisitions in the commercial field (see Field and Peck, 2003). Cartwright and Cooper (1996) have examined the cultural characteristics of companies and how these can affect the outcomes of mergers and acquisitions. They argue that the degree of 'cultural fit' can be critical in determining the outcome of a merger or an acquisition; they also suggest that most fail and that poor cultural fit between the new partners - leading to staff experiencing a loss of morale and a loss of commitment - is the main cause.

\section{What do we mean by organisational culture?}

Most accounts of culture assume what Meyerson and Martin (1987) call an integration model. This sees culture as something that organisations possess and which is therefore broadly recognisable and consistent across them. On this view, culture is an influence which promotes integration within organisations (thus two divergent cultures may need to be reconciled when organisations work in partnership) and may be manipulated in relatively predictable ways in order to enhance integration. 
A few examples of this school of thought will establish its basic premises. One of the most frequently cited authors on organisations, Schein (e.g. 1985), suggests that organisational culture can be thought of as the shared basic assumptions that an organisation learns as it solves problems of adaptation and integration (or as Ouchi and Johnson, 1978, put it: 'the way we do things around here'). These assumptions are considered to be 'valid' and are taught to new members as the correct way to perceive, think, feel or act. There is broad agreement within the more thoughtful parts of this literature that organisational cultures are multi-layered, consisting of a central core that is overlaid with more superficial and easily influenced outer layers (e.g. Schein, 1985; Hofstede, 1991). The broad generalisations that such conceptions of culture generate can be very plausible (see Peck and Crawford, 2004, for more discussion of these in relation to health and social care).

A second approach identified by Meyerson and Martin (1987) conceptualises culture as more pluralistic, with disparate cultures being held by different interest groups within the same organisation. On this view, culture is an influence which may once again inhibit integration (and thus partnership), but where the various cultures may be open to manipulation, in particular in relation to the ways in which they interact. This is the difference model of culture.

Most health care organisations are composed of numerous and disparate professional cultures. Indeed, the mix of managerial and professional cultures in which multiple values coexist alongside power imbalances among the various staff groups has been seen as the key distinctive feature of the UK National Health Service (NHS) (Harrison et al., 1992; Dawson, 1999). In such a context, there are risks in any attempt to develop a strong unitary culture which may overlook the richness within the pre-existing cultures and the complex meaning-making processes that they enable (Hawkins, 1997). Peck and Norman (1999) provide a summary of significant aspects of professional cultures as manifested in community mental health services in London in the late 1990s. This notion of difference - of defining who I am in distinction from who you are - is one of the key components of professional culture. It may not be one that it is wise to assume should always be challenged (e.g. boundaries between professionals should not necessarily be characterised as barriers to better services; see Peck et al., 2001).

The third perspective discussed by Meyerson and Martin (1987) - the ambiguity model - considers culture to be more local and personal than the other two, constantly being negotiated and re-negotiated between individuals and groups within the organisation. These patterns of creation and re-creation of culture may be influenced by the organisation within which, and by the interest groups between which, they take place, but it is the one that perhaps offers the least prospect of predictable manipulation. Although this aspect may be the most opaque to observers, there was evidence from an evaluation of a mental health partnership between a health authority and a county council in the UK (Peck et al., 2001) to support the importance of this level of culture in health and local government. There was considerable ambiguity around individual views of the trust and many staff felt that their relationship with other staff groups was largely dependent, as one employee put it, 'on the person'. On this account, culture is an enactment neither of organisational 
assumptions nor of professional subculture, but rather the ebb and flow of individual relationships.

In their study of partnership development in Somerset, Peck et al. (2001) identified the presence of all three of these levels of culture. Broadly, discussions with managers revealed an assumption of an integration model of culture, those with professional groups focused on professional difference and those with staff in localities suggested considerable negotiation and re-negotiation of culture, consistent with the ambiguity model. Clearly, therefore, deploying this framework has potential for aiding both interpretation of and intervention in culture. It is perhaps also worth noting that despite the language of partnership that runs through the research of Peck and his colleagues, this study focused on what is best described as a process of merger between health and social care.

It is also important to acknowledge the origins of the idea in anthropology, where the classical anthropological understanding of culture refers to institutionalised practices and accountabilities located within social structures (see Moore, 1997). Whether analysing whole societies or specific organisations, many anthropologists have argued that ideas and beliefs - the visible manifestations of culture - are to be explained by reference to the social structure in which they occur. Exploring this relationship between social structure and organisational culture in an English NHS Trust, Bate et al. (2000) describe the co-evolution of culture and structure, each shaping and in turn being shaped by the other. This link between culture and structure is clearly important for the discussion of culture in partnership organisations where the creation of new organisational forms inevitably changes the practices and accountabilities in ways that may be open to manipulation by managers.

\section{The international evidence on culture in health and social care partnerships}

The international health and social care partnership literature reflects the view that culture plays a vital role in creating effective partnerships. As suggested in the introduction to this chapter, this probably links to a wider private sector literature which proposes that culture plays an imperative part in the merger and acquisition process (e.g. Kilmann et al., 1985; Bueno and Bowditch, 1989; Bijlsma-Frankema, 2001; see also Box 1.1 for key definitions). Private sector companies tend to put a large degree of effort into assessing and auditing the cultures of potential merger partners to check that it is compatible with their own (Dickinson et al., 2006). What this implies is that culture is a 'component' that an organisation 'has' as an internal variable. Consequently, a number of typologies of cultures have been produced and are widely employed as they help 'make sense' of the organisation and typify the organisational 'style'. Such taxonomies usually comprise four elements (see, e.g., Handy, 1976; Pheysey, 1993; Schneider, 1994; Cartwright and Cooper, 1998) and are presumably so popular as they are simple to explain and make accessible to busy practitioners (Peck and Crawford, 2004). 


\section{Box 1.1 A note on terminology.}

In this chapter we refer to mergers and acquisitions, particularly when drawing on literature from the private sector. This box gives an overview of what these two phenomena entail.

Mergers. Mergers intuitively seem to be a fairly simple concept. McClenahan and Howard $(1999$, p. 4) define a merger as 'the coming together into a single corporate body of two or more previously separate organisations'. However, Baskin et al. (2000) suggest a more complicated picture than this, stating that there are three different kinds of mergers:

Partition. Managers assume that everything can continue as it has, with merged units operating side by side. This approach overlooks the tension that putting the units together may cause, and serious conflict results.

Domination. One organisation and its culture take over another. This approach can often result in debilitating resentment in the 'defeated'.

Synthesis. Through careful planning, design and execution, managers in the merging companies try to synthesise the best elements of each into a higher, superordinate harmony.

Furthermore, mergers may also be horizontal (i.e. companies with similar product types) or vertical (i.e. merger of a vendor and a customer). Therefore, although a merger is technically a coming together of two or more organisations, the depth and the extent to which these organisations merge may have very different connotations for the organisations in practice.

Acquisitions. An acquisition constitutes acquiring control of an organisation, usually called a target, by stock purchase or exchange. Like merger, this seems like a simple enough term in itself, but is made up of horizontal and vertical acquisitions, in the same way to mergers. There is also a further dimension regarding the mode of acquisition: hostile or uncontested. Hostile acquisitions, where the organisation is less than receptive to the proposal - often referred to as a takeover-tend to lead to less successful outcomes (Strower, 1998). However, some authors would argue that all mergers are acquisitions (McClenahan and Howard, 1999) due to the differing sizes of organisations and their relative resources. In the Introduction to this book, Glasby and Dickinson outlined the depth-breadth matrix, and this may be useful to use in thinking through where mergers and acquisitions sit in terms of other forms of partnership relationships.

The cultural typology literature stresses the danger of clashes of organisational culture on the grounds that it can lead to merger failure (Kilmann et al., 1985; Chatterjee et al., 1992; Atkinson, 2005). The literature suggests that organisations have such fundamentally different ways of framing issues, reacting to problems, enacting procedural rules and pursuing management styles that bringing such different 
cultures together can lead to a situation of 'us vs them' (Marks and Mirvis, 1992). Finding similar organisational cultures has become a common panacea for avoiding employee dissatisfaction - which could potentially undermine the success of a merger (Larsson, 1993). Ashkenas et al. (1998) provide a case study of a private company who walked away from a potential merger very late in proceedings despite favourable financial prospects - on realising that differences in management cultures could make such a move very difficult. Many of these organisations use 'cultural audits' to identify any significant differences or similarities between core values, beliefs, attitudes and management styles of the organisations prior to change (Salama et al., 2003).

Much of this literature stresses that enforced integration does not work. One partner is usually always dominant within partnership arrangements (even if only in size), and this could potentially instil a feeling of 'takeover' in one set of staff (McClenahan and Howard, 1999; see also Box 1.1). If the culture of the stronger party is imposed, it is suggested that tension, distrust and annoyance will result (Weber and Schweiger, 1992). A process of cultural audit is thought to guard against such a feeling of takeover; if aspects of good practice from both organisations are taken on by the new entity, then both can show that they have something positive to contribute to the process. Therefore, much of this literature assumes the integration model; by finding a partner with a similar culture, partnership working will be enhanced and any residual differences in culture can be manipulated.

However, although the issue of culture-fit is important, it is further suggested that too much 'fit' can reduce the synergetic effects expected from the merger process (Bijlsma-Frankema, 2001). Mergers are intended to produce effects which are bigger than the sum of the organisations involved in the process (much in the same way that health and social care partnerships are often promoted on the grounds that they produce synergy or 'collaborative advantage'; .Huxham and Vangen, 2005). In the private sector, mergers are thought to offer a good opportunity to challenge the assumptions and processes of individual organisations and find new and more effective ways of delivering services (Marks, 1997). If cultures are too similar, the product is effectively an extension of existing organisations, rather than the creation of some new and different entity.

Despite the importance that culture seems to have assumed within the public sector partnership literature, a surprisingly small proportion of the international literature discusses culture in anything more than a normative, coherent and unproblematic fashion. Although culture is frequently cited as an important factor within the process of partnership working, there is little consideration of what form precisely this factor takes (see, e.g., Hensing et al., 1997; Hultberg et al., 2002). Moreover, within these studies, culture tends to appear as somewhat of an afterthought: that is, post hoc, culture is suggested as the reason why the partnership was not as effective or did not conclude in the anticipated results (see, e.g., Timpka et al., 1995; McCloughen and O'Brien, 2006). In other words after the event, the neglect of cultural factors is recognised as having played a potentially detrimental role in the effectiveness of the partnership. 
In this way, the most common accounts from the international public sector partnership literature report the difference model of culture in practice, whilst operating under the assumption that an integration model would have created a more effective partnership. One such account is the report of an attempt to integrate health and social care management structures in the English boroughs of Barking and Dagenham. Wistow and Waddington (2006) report how this process ran into difficulties due to 'basic incompatibilities, largely derived from the mismatch in cultures' (p. 14). In the process, Wistow and Waddington summarise the characteristics of the NHS and social services partners (illustrated in Table 1.1). These are not uncommon characterisations of health and social care and relate in part to the differing professional 'models' of care which are frequently typified as underpinning health and social care.

In this case, the cultures are further described as being closely linked into the performance management systems and the national policy objectives which broadly frame these partners within much wider organisational contexts than the local area alone. It is suggested that these divergent underpinning expectations and values form an inherent barrier to creating partnerships between these organisations. Although local partners were not able to influence the separate NHS and local government accountability and priority-setting mechanisms, the research team suggest that more attention to changing cultures by identifying areas of differences and developing agreed strategies for managing them might have resulted in more effective partnership working. In this case, Wistow and Waddington suggest that too much attention was paid to the structure of the partnership, with insufficient attention paid to cultural factors. Thus, although the research from the locality suggests the difference model of culture, the researchers advocate an integration model in attempting to produce a more 'effective' partnership.

Writing from a Canadian perspective, Hall (2005) provides a historical overview of the growth of professional cultures - not only between health and social care organisations, but also intra-organisational differences in cultures - for example, between nurses and physicians. Some professional cultures are typified as possessing values which run counter to the spirit of collaboration due to the high value which they place on autonomy (Gage, 1998) and these constructions of culture largely cleave to the difference model (consonant with the findings of Peck and Norman, 1999). However, Hall argues that these differences not only pertain to the different models of health care underpinning these professions (as outlined earlier),

Table 1.1 Differences in characterisation of NHS and social services partners.

\begin{tabular}{ll}
\hline NHS & Social services \\
\hline Treatment & Care \\
National targets & Local needs \\
Must dos & Local discretion \\
Universal services & Focus on vulnerable \\
Procedurally regimented and very & Practical focus but has difficulty with \\
top-down in style & strategy and planning \\
\hline
\end{tabular}

Adapted from Wistow and Waddington (2006, p. 14). 
but also relate to deeply engrained factors such as class and gender. (Morrow et al., 2005, also report similar findings in relation to multi-agency working in children's services.) In this way, the ambiguity model of culture is suggested and this is supported by Hojat et al. (2001) in a study of nurse-physician collaboration in the US and Mexico where the researchers demonstrate spatial and temporal variation in these professional cultures.

Similar conclusions are reached in Kharicha et al.'s (2005) study of general practitioner-attached social workers. Cultural differences are cited as existing between medical and social models, and these manifested themselves through a lack of understanding of and clarity over each other's roles, responsibilities, pressures and organisational procedures (often with regard to specific incidents). The researchers report a number of strategies which social workers used to overcome these difficulties, such as risk minimisation, conceding on policy and accepting pragmatic solutions, using nurses as mediators and resorting to hierarchical authority. Moreover, they report social workers expressing a real fear that by being absorbed into the practice teams, they would have difficulty working to social services priorities, agendas and entry criteria as they integrate into the culture. Therefore, although the social workers reported the difference model in terms of everyday practice, they were also acutely aware of the potential for the ambiguity model of culture to occur with its processes of negotiation and re-negotiation of cultures.

In addition to the Somerset example cited earlier, another study demonstrates the presence of all three models of culture. Cruser and Diamond (1996) studied a medical health programme at the Harris County Jail in the US. In this case mental health staff were placed into criminal justice settings, and the authors report clear professional differences between their cultures. The research team employed an organisational culture (OC) schema based on Diamond's theory of organisational cultures (Diamond, 1993). This schema contains four OC models, each of which defines the degree to which the mental health system takes responsibility for problems and solutions associated with offenders with mental impairments (illustrated in Figure 1.1). Each of the models represents a way of the partnership relating to the external environment as a manifestation of the way in which the mental health and criminal justice agencies are able to work together in partnership.

This approach suggests that the partners' abilities to interact with each other in understanding or being able to deal with the other's different value bases inform the culture of the partnership in its dealings with the outside world. According to this thesis, the institutional and autocratic models are isolated from the environment, the homogenised model is paralysed in its ability to interact with the environment but the resilient model is empowered to communicate with the environment. Although the OC model is used, Cruser and Diamond recognise that it is essentially a heuristic schema and that in practice culture is a product of individual self-systems and unconscious values may be more dynamic and diffuse than this 'ideal' type. In this way, Cruser and Diamond recognise the ambiguity model at the level of individual practice.

At the start of the project, the Harris County Jail was characterised as having a mixed OC model, and the partners related to each other differently in a number 


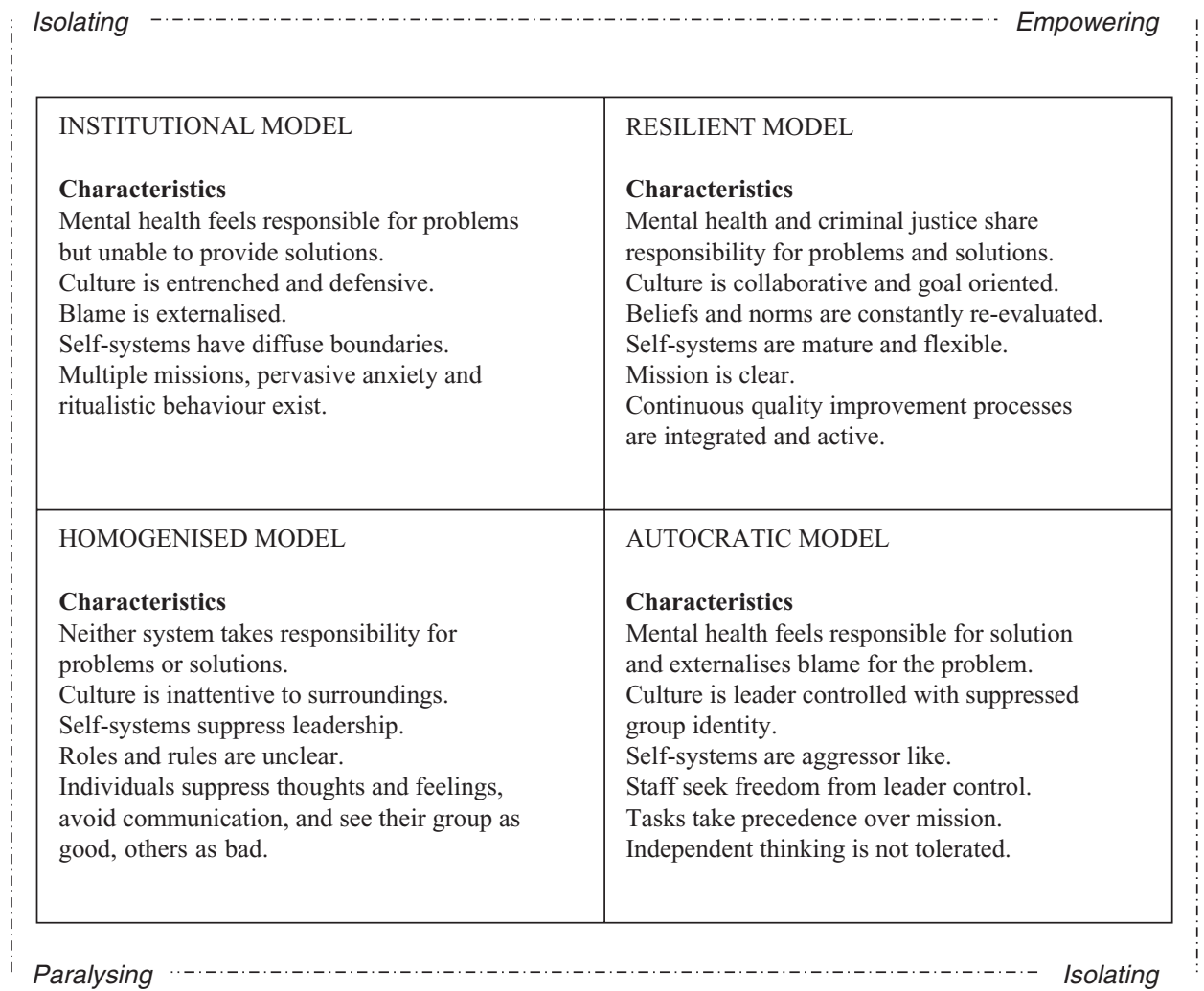

Figure 1.1 The organisational culture schema. (Adapted from Cruser and Diamond, 1996, p. 141.)

of different parts of the system. However, the management brought in a series of changes to the environment, leadership, human resources management, training and roles of staff members in an attempt to alter the OC model to a fully resilient model - that is the management assumed an integration model in an attempt to modify the culture of the partnership.

\section{What interventions shape culture?}

There are a number of messages from the international literature which are important in thinking about interventions in culture. Most strikingly, it is clear that culture becomes particularly important when a merger of two (or indeed more) cultures is proposed; indeed, two key questions arise.

Firstly, is the management of culture possible? It appears that the difference and ambiguity views of culture offer less hope to the would-be manipulators of culture than the integration model. Parker (2000) offers two conclusions from his review of the culture literature (and his case studies based in health care settings): the first is 
that 'cultural management in the sense of creating an enduring set of shared beliefs is impossible' (p. 228); on the other hand, he suggests that 'it seems perverse to argue that the "climate", "atmosphere", "personality", or culture of an organisation cannot be consciously altered' (p. 229). This is broadly the view adopted in the rest of this chapter, although it also acknowledges - along with Bate et al. (2000) - the poor track record of corporate cultural change programmes that do not simultaneously look at the prospects for changes in practices and accountabilities where social structures are also amended.

Secondly, is structural change, therefore, enough to change culture? It would appear that structural change - the predominant tool for cultural change in Somerset, for example - may not be enough; the creation of a partnership trust (and associated innovations such as the co-location of health and social care staff) was not in itself a sufficient condition to create the desired cultural changes during the first 3 years (albeit that might be an optimistic timeframe within which to expect such changes). Indeed, in the short-term at least, structural change may have served to strengthen attachment to existing professional cultures (see Peck et al., 2002). With these caveats in mind, this section now examines a range of tools for and approaches to interventions in culture in organisations.

In a systematic review of quantitative measures of organisational culture that have either been validated and used in health care settings or appear to have potential for use in such settings, Scott et al. (2003b) identify a total of 13 instruments (illustrated in Box 1.2). Scott and his co-authors (2003a) argue for the pragmatic selection of an instrument based on the purpose and context of any assessment. They identify four things to think about in utilising these tools:

- Levels (i.e. are you looking at the central core or more superficial manifestations?)

- Triangulation (i.e. are you drawing messages following comparisons of data from various sources?)

- Sampling (i.e. are you asking a representative number of staff?)

- Analysis (e.g. are you going to explore the results by professional group or by geographical locality?)

In an account of an intervention in the creation of a care trust (i.e. an integrated English health and social care organisation), Peck and Crawford (2004; see also Peck and 6, 2006) report on the use of a specifically designed cultural audit tool. The aim of the intervention was to establish perceptions of existing NHS and social services organisational cultures and aspirations for the organisational culture within the care trust. It is perhaps telling the extent to which staff identified innovations in the social structure (e.g. supervision arrangements and IT systems) as central to the delivery of their cultural aspirations for the care trust; it appears that staff already recognised the importance of the interplay between structure and culture as discussed by Bate and colleagues (2000). At the same time, there were some suggestions - such as creating a 5-year vision for the merged organisation - that were not dependent on structure at all. Furthermore, the managers took to heart one of the key messages in the 'culture cookbooks' on mergers: 
Box 1.2 Quantitative organisational culture measures.

Typological approaches:

- Competing values questionnaire

- Harrison's organisational ideology questionnaire

- Quality improvement implementation survey

Dimensional approaches:

- Organisational culture inventory

- Hospital culture questionnaire

- Nursing unit culture assessment tool

- Practice culture questionnaire

- MacKenzie's culture questionnaire

- Survey of organisational culture

- Corporate culture questionnaire

- Core employee opinion questionnaire

- Hofstede's organisational culture questionnaire

- Organisational culture survey

After Scott et al. (2003b).

that staff from the two agencies merging should be given as many opportunities as possible to meet in so-called transitional groups to explore preconceptions and perspectives (see Peck and Smith, 2006, for a discussion of this and other messages).

Of course, this cultural analysis was itself an intervention in culture. As one consequence, staff reflected on the changes in culture that they wanted to see addressed through alterations in social structure; many of these focus on the assumptions that divide health care from social care and profession from profession. The very process of such reflection can be assumed to have generated some commitment to change; certainly, it highlighted for managers the issues where staff wanted them to take action and simultaneously created some legitimacy for such action. Overall, Dickinson et al. (2007) conclude that leaders in this case study adopted an integrationist view of culture. In doing so, consistency remained a key message to staff throughout this organisational transition and the change did not appear to cause the distraction to core business which the literature suggests it would. However, this continuity may have come at a cost, at least initially. In the process of formalising the previous partnership into a care trust, these leaders may not have produced all the beneficial effects of synergy which are usually (albeit eventually) associated with mergers in the private sector. Certainly, 
local actors could see opportunities that had been missed. This study serves to confirm that the integrationist conception of culture is limited and that the differentiation of professional groupings and the ambiguity of individual experience will always make contested the meanings that are attributed to organisational change.

Nonetheless, local leaders acknowledged the perceived threat to social care values arising from the location of social care staff in health settings which was expressed as clearly in this locality as it was in the research of Peck and Norman (1999). To address this concern, managers identified one of the central cultural issues for social care staff as relating to the response to diversity; the core assumption of social care is that the negative life experiences of clients should be challenged and the manifestation is that social care staff must receive training in anti-discriminatory practice. As a consequence, all new recruits to the care trust - regardless of professional background - receive such training as part of their induction. Of course, such training may not overcome counter-cultural values and assumptions held by either professions or individuals, but this initiative has both an instrumental and a symbolic purpose that is viewed as crucial to the care trust culture manifesting social care values and assumptions.

As suggested in the Introduction to this chapter, a number of commentators from the commercial sector (e.g. Cartwright and Cooper, 1996) have suggested that the majority of mergers and acquisitions fail in practice. Such commentators typically define the degree of success or failure predominantly within financial terms, yet suggest that the reason for this failure is a preoccupation with structures at the expense of the 'human factor' (culture). However, this may in fact be a false dichotomy. Peck and 6 (2006) suggest that the divergent institutional practices and accountabilities around budgeting arrangements and performance management of financial targets that impact upon health and social care agencies (as also demonstrated by Wistow and Waddington, 2006; see earlier) are a major influence on the cultures of the partners so that cultural and financial issues are closely intertwined. This is further demonstrated through Johri et al.'s (2003) study of international experiments with integrated care. The team looked at integrated care programmes and demonstrations from the UK, the US, Italy and Canada and draw common features of effective integrated care from these case studies. One of the critical features of these programmes is the use of financial levers (see also Chapter 5). Typically, this is exemplified by the integrated care programme taking responsibility for a set of risks associated with working together, but with the financial rewards should they save money through appropriate downward substitution (e.g. in the case of care of older people, reducing institutional expenditure through supporting individuals within their own homes).

Partnership working has a tendency to be predicated on a notion that it will improve outcomes for those that use services (see Chapter 11 for further discussion) and as such issues of finance tend to be much less discussed - publicly and rhetorically at least. However, this chapter argues that partnership culture is in part shaped by and intertwined with not only the structures but also the institutional 
arrangements of partners. Thus, any attempts to intervene or shape culture must take account of these factors within fairly wide contexts.

\section{Conclusion}

It is apparent that health and social care organisations - and their staff - approach new partnership arrangements (be they genuine partnerships, mergers or, indeed, acquisitions) with well-established perceptions - both positive and negative - of each other. These perceptions, and in particular the points of tension, are often expressed in terms of culture. Further, it is clear that culture plays a major role in the success or failure of partnerships. The process of creating and sustaining new partnership forms between health and local government thus needs to pay careful attention to culture.

The management literature contains many examples of claimed 'makeovers' of organisational culture (e.g. Shirley, 2000; Bernick, 2001), and these may prove illuminating to those seeking to address organisational dysfunction apparently rooted in poor fits between cultures. Yet, the claims of the champions of culture as a tool for integration are often overstated and the potential for interventions to have a transformational effect on organisational culture(s) is limited. It is for these reasons that Davies et al. (2000) urge a cautious reassessment of the possibilities for cultural transformation in the UK NHS which would involve sensitivity to subcultural differences, honouring current achievements and consideration of the needs, fears and motivations of diverse staff groups. Nonetheless, Ogbonna and Harris (2000), following Martin (1985), argue that organisational culture cannot be managed but may be manipulated under specific contingencies (including the formation of an organisation, periods of crisis and during leadership turnover). This seems a plausible conclusion, consistent with the position of most thoughtful commentators (e.g. Parker, 2000), and one that highlights the opportunities that face managers and practitioners during the creation of partnership arrangements and organisations.

Of course, any health and social care partnership is working with several professional cultures - with difference - as well as with (at least) two organisational cultures. Regardless of the organisational form chosen, any strategy to manipulate organisational culture in health and local government will have to work with, and through, these professionals and their cultures. In these circumstances, managers should not be lured by the culture cookbooks into assuming that all tension deriving from cultural difference within organisations is either unhealthy and/or avoidable. At the same time, Bate et al. (2000), and the case study in the preceding section, draw attention to the importance of innovations in social structure in potentially mediating the impact of these cultures.

Finally, is there a clear link between organisational culture and organisational performance? From their exhaustive study in health care, Scott et al. (2003b) decide 
that empirical studies do not provide clear answers, whilst noting that the available research is small in quantity, mixed in quality and variable in methodology (thus making comparisons between studies difficult). This is of course very different to the confident assertions of the authors of the culture cookbooks. However, it seems counter to our intuition and our experience to deny any such link, challenging as this may be to prove to the satisfaction of researchers. Ultimately, consideration of both the literature and previous experience suggests that through reflecting on and intervening in organisational culture(s) with sense and sensitivity, partially through re-designing social structures when opportunities arise, managers and practitioners can achieve some change in that culture, whilst being aware that such interventions may well have unanticipated aspects.

\section{Summary}

- In discussions of partnership working between health and social care, one issue seems to recur more than any other: culture.

- There is compelling evidence that culture is also a central issue in the success of alliances, mergers and acquisitions in the commercial field. In this context it is often suggested that mergers and acquisitions fail due to the precedence of structural over human (cultural) factors.

- Culture is a complex concept with many different underpinning models suggested by various commentators, but typically tends to be treated in a rather normative or coherent fashion in practice.

- Meyerson and Martin's (1987) distinction between three models of culture (integration, difference and ambiguity) is useful in thinking about concepts of culture within a partnership context.

- The commercial sector (and a number of management 'cookbooks') tend to point to the importance of 'culture-fit' and suggest tools such as cultural audits to make mergers and acquisitions 'work'. However, there is a danger that too much fit might reduce the synergetic effects associated with mergers.

- In the public sector, different professional values, models of care and performance management and regulatory systems are all illustrated as factors which inform differing health and social care cultures and form barriers to partnership working. However, it cannot be assumed that breaking these down is necessarily the most effective tactic to overcome these differences.

- Structural change alone seems to be an insufficient condition to create cultural change. Indeed, in the short-term at least, structural change may serve to strengthen attachment to professional cultures.

- There is little empirical evidence from health and social care linking culture and organisational performance, although implicitly it seems likely that there is some form of association.

- Organisational culture change may be achieved partially through redesign of social structures, but such interventions may also have impacts which are not predicted at the outset. 


\section{Further reading and useful websites}

\section{Useful texts include:}

Bate P. (1995) Strategies for Cultural Change. Oxford, Butterworth-Heinemann.

Meyerson, D. and Martin, J. (1987) Cultural change: an integration of three different views, Journal of Management Studies, 24, 623-643.

Parker, M. (2000) Organisational Culture and Identity. London, Sage.

Schein, E. (1985) Organizational Culture and Leadership. San Francisco, Bass.

\section{Relevant websites include:}

The Integrated Care Network has publications supporting partnership and integrated working within the UK, including a discussion paper on culture and partnership working: http:/ / www.integratedcarenetwork.gov.uk

Aston Organisation Development is a spin out company from Aston Business School that hosts a wealth of resources and information focused on the evidence around effective team-based working: (http:/ / www.astonod.com/index.php)

Inter-logics is a multidisciplinary consulting practice specialising in work with complex organisations and multi-agency partnerships: (http://www.inter-logics.net/default.aspx)

\section{References}

Ashkenas, R.N., DeMonaco, L.J. and Francis, S.C. (1998) Making the deal real: how GE Capital integrates acquisitions, Harvard Business Review, 7, 165-178.

Atkinson, P. (2005) Managing resistance to change, Management Services, 14-19.

Baskin, K., Goldstein, J. and Lindberg, C. (2000) Merging, de-merging, and emerging at Deaconess Billings Clinic, Physician Executive, 26, 20-26.

Bate, P., Khan, R. and Pye, A. (2000) Towards a culturally sensitive approach to organizational structuring: where organization design meets organization development, Organization Science, 11, 197-211.

Bernick, C.L. (2001) When your culture needs a makeover, Harvard Business Review, 79, 53-61.

Bijlsma-Frankema, K. (2001) On managing cultural integration and cultural change processes in mergers and acquisitions, Journal of European Industrial Training, 25, 192207.

Bueno, A.F. and Bowditch, L. (1989) The Human Side of Mergers. San Francisco, Jossey-Bass.

Cartwright, S. and Cooper, C.L. (1996) Managing Mergers, Acquisitions and Strategic Alliances: Integrating People and Culture. Woburn, MA, Butterworth-Heinemann.

Cartwright, S. and Cooper, C.L. (1998) Company cultures in M\&A, The Antidote, 3, 3133.

Chatterjee, S. et al. (1992) Cultural differences and shareholder value in related mergers: linking equity and human capital, Strategic Management Journal, 7, 119-140.

Cruser, D.A. and Diamond, P.M. (1996) An exploration of social policy and organizational culture in jail-based mental health services, Administration and Policy in Mental Health, 24, 129-148.

Davies, H.T., Nutley, S. and Mannion, R. (2000) Organisational culture and quality of health care, Quality in Health Care, 9, 111-119. 
Dawson, S. (1999) Managing, organising and performing in health care: what do we know and how can we learn? in A. Mark and S. Dopson (eds) Organisational Behaviour in Health Care. London, Macmillan.

Diamond, P.M. (1993) The Unconscious Life of Organizations: Interpreting Organizational Identity. Westport, CT, Quorum Books.

Dickinson, H., Peck, E. and Davidson, D. (2007) Opportunity seized or missed? A case study of leadership and organizational change in the creation of a care trust, Journal of Interprofessional Care, 21, 503-513.

Dickinson, H., Peck, E. and Smith, J. (2006) Leadership in Organisational Transition - What Can We Learn from Research Evidence? Summary Report. Birmingham, Health Services Management Centre.

Field, J. and Peck, E. (2003) Mergers and acquisitions in the private sector: what are the lessons for health and social services? Social Policy and Administration, 37, 742755.

Gage, M. (1998) From independence to interdependence, Journal of Nursing Administration, $28,17-26$.

Hall, P. (2005) Interprofessional teamwork: professional cultures as barriers, Journal of Interprofessional Care, May, 188-196.

Handy, C. (1976) Understanding Organizations. London, Penguin.

Harrison, C. et al. (1992) Just Managing: Power and Culture in the National Health Service. London, Macmillan.

Hawkins, P. (1997) Organizational culture: sailing between evangelism and complexity, Human Relations, 50, 417-441.

Hensing, G., Timpka, T. and Alexandersson, K. (1997) Dilemmas in the daily work of social insurance officers, Scandinavian Journal of Social Welfare, 6, 301-309.

Hofstede, G. (1991) Cultures and Organisations: Software of the Mind. London, McGrawHill.

Hojat, M. et al. (2001) Attitudes toward physician-nurse collaboration: a cross-cultural study of male and female physicians and nurses in the United States and Mexico, Nursing Research, 50, 123-128.

Hultberg, E.-L., Lonnroth, K. and Allebeck, P. (2002) Evaluation of the effect of co-financing on collaboration between health care, social services and social insurance in Sweden, International Journal of Integrated Care, 2. Available online via www.ijic.org

Huxham, C. and Vangen, S. (2005) Managing to Collaborate: The Theory and Practice of Collaborative Advantage. Abingdon, Routledge.

Johri, M., Béland, F. and Bergman, H. (2003) International experiments in integrated care for the elderly: a synthesis of the evidence, International Journal of Geriatric Psychiatry, 18, 222-235.

Kharicha, K. et al. (2005) Tearing down the Berlin wall: social workers' perspectives on joint working with general practice, Family Practice, 22, 399-405.

Kilmann, R.H., Saxton, M.J. and Serpa, R. (1985) Gaining Control of the Corporate Culture. San Francisco, Jossey-Bass.

Larsson, R. (1993) Barriers to acculturation in mergers and acquisitions: strategic human resource implications, Journal of European Business Education, 2(2), 1-18.

Marks, M.L. (1997) Consulting in mergers and acquisitions: interventions spawned by recent trends, Journal of Organizational Change, 10, 267-279.

Marks, M.L. and Mirvis, P.H. (1992) Rebuilding after the merger: dealing with 'survivor sickness', Organizational Dynamics, 21(2), 18-32. 
Martin, J. (1985) Can organizational culture be managed? in P. Frost, et al. (eds) Organizational Culture. London, Sage.

McClenahan, J. and Howard, L. (1999) Healthy Ever After? Supporting Staff through Merger and Beyond. Abingdon, Health Education Authority.

McCloughen, A. and O'Brien, L. (2006) Interagency collaborative research projects: illustrating potential problems, and finding solutions in the nursing literature, International Journal of Mental Health Nursing, 15, 171-180.

Meyerson, D. and Martin, J. (1987) Cultural change: an integration of three different views, Journal of Management Studies, 24, 623-643.

Moore, J.D. (1997) Visions of Culture: An Introduction to Anthropological Theories and Theorists. London, AltaMira.

Morrow, G., Malin, R. and Jennings, T. (2005) Interprofessional teamworking for child and family referral in a Sure Start local programme, Journal of Interprofessional Care, 19, 93101.

Ogbonna, E. and Harris, L.C. (2000) Leadership style, organizational culture and performance: empirical evidence from UK companies, The International Journal of Human Resource Management, 11, 766-788.

Ouchi, W. and Johnson, A. (1978) Types of organisational control and their relationship to organisational well-being, Administrative Science Quarterly, 23, 292-317.

Parker, M. (2000) Organisational Culture and Identity. London, Sage.

Peck, E. and Crawford, A. (2004) 'Culture' in Partnerships - What Do We Mean by It and What Can We Do About It? Leeds, Integrated Care Network.

Peck, E., Gulliver, P. and Towell, D. (2002) Modernising Partnerships: An Evaluation of Somerset's Innovations in the Commissioning and Organisation of Mental Health Services. London, Institute of Applied Health and Social Policy, King's College.

Peck, E. and Norman, I.J. (1999) Working together in adult community mental health services: exploring inter-professional role relations, Journal of Mental Health, 8, 231-242.

Peck, E. and 6, P. (2006) Beyond Delivery: Policy Implementation as Sense-Making and Settlement. Basingstoke, Palgrave Macmillan.

Peck, E. and Smith, J. (2006) A bit of a blur? How to handle change, Health Service Journal, 116, 22-23.

Peck, E., Towell, D. and Gulliver, P. (2001) The meanings of 'culture' in health and social care: a case study of the combined trust in Somerset, Journal of Interprofessional Care, 15, 319-327.

Pheysey, D. (1993) Organizational Cultures: Types and Transformations. London, Routledge.

Salama, A., Holland, W. and Vinten, G. (2003) Challenges and opportunities in mergers and acquisitions: three international case studies - Deutsche Bank-Bankers Trust; British Petroleum-Amoco; Ford-Volvo, Journal of European Industrial Training, 27, 313-321.

Schein, E. (1985) Organizational Culture and Leadership. San Francisco, Bass.

Schneider, W. (1994) The Reengineering Alternative: A Plan for Making Your Current Culture Work. Oxford, Radcliffe Press.

Scott, T. et al. (2003a) Healthcare Performance and Organisational Culture. Oxford, Radcliffe Medical Press.

Scott, T. et al. (2003b) The quantitative measurement of organisational culture in health care: a review of the available instruments, Health Services Research, 38, 923-945.

Shirley, J. (2000) Clinical governance in an independent hospital, Clinician in Management, 9 , 229-233.

Strower, M.L. (1998) M\&A: not for the average company? The Antidote, 8-9. 
Timpka, T., Hensing, G. and Alexandersson, K. (1995) Dilemmas in sickness certification among Swedish physicians, European Journal of Public Health, 5, 215-219.

Weber, Y. and Schweiger, D.M. (1992) Top management culture conflict in mergers and acquisitions: a lesson from anthropology, The International Journal of Conflict Management, 3, 285-302.

Wistow, G. and Waddington, E. (2006) Learning from doing: implications of the Barking and Dagenham experiences for integrating health and social care, Journal of Integrated Care, 14, 8-18. 